\title{
IMPACTOS DAS ENERGIAS SOLAR E EÓLICA NA DEMANDA DE BATERIAS DE LÍTIO'
}

José Mauro de Morais²

\section{SINOPSE}

O principal uso de baterias de lítio nos sistemas de energia renovável ocorre nos sistemas solares off grid, e a demanda por essas baterias é impulsionada por fatores como instalaçóes de sistemas em localidades não alcançadas por redes de eletricidade, substituição de baterias de chumbo e a necessidade de estabilização da rede por baterias para corrigir oscilaçóes e interrupçóes de energia. A maior parte da demanda nacional por baterias de lítio é suprida por importaçóes, havendo apenas um pequeno fabricante nacional. As projeçóes de expansão da produção de energia solar no Brasil indicam um caminho de expansão crescente dessa demanda ao longo das próximas décadas.

Palavras-chave: bateria de lítio; baterias; off grid; geração distribuída.

O uso de baterias de lítio nos sistemas de energia renovável ocorre basicamente nos sistemas solares off grid, uma vez que os grandes sistemas de geração solar centralizada e os sistemas de micro e minigeraçáo distribuída on grid ligam-se diretamente à rede de energia elétrica, que funciona como bateria para esses sistemas. Os sistemas on grid não representam, portanto, mercado significativo para baterias de lítio, pelo menos no presente.

A energia eólica, por sua vez, é caracterizada por grandes sistemas de geração ligados às redes elétricas, e não utiliza baterias. Os sistemas menores de geração distribuída (GD) eólica podem necessitar de bateria, porém têm participação ínfima $(0,1 \%)$ na geração eólica como um todo, não impactando a demanda por baterias.

A demanda por baterias de lítio nos sistemas solares off grid é impulsionada por fatores como:

- instalações de sistemas em localidades não alcançadas por redes de eletricidade, em que é alto o custo de conexão à rede e em regióes isoladas;

- propriedades agrícolas ou pontos de propriedades agrícolas sem rede;

- substituição de baterias de chumbo; características da oferta de energia elétrica no país, com a necessidade de estabilização da rede por baterias para corrigir oscilaçóes, ou interrupçóes de energia em períodos de tempo mais longos; e

- situações em que é necessária independência em relação à rede elétrica por questôes de segurança no fornecimento.

Também se espera que, no médio prazo, com redução significativa do preço das baterias de lítio, poderá ocorrer a substituição de motores a diesel, hoje muito utilizados por consumidores atendidos em alta tensão com alto fator de carga na ponta para evitar o consumo e a alta tarifa em horários de ponta (EPE, 2020).

Consultas que realizamos ao mercado revendedor de baterias de lítio para os sistemas solares confirmaram as utilizaçóes acima. Foram contatadas as empresas Solius Solar, Unipower e Aldo Solar, que importam baterias para a comercialização no mercado, especialmente da China, pois a oferta de baterias nacionais é muito pequena. A parcela maior do mercado comprador é representada por sistemas off grid equivalentes à microgeração distribuída (potência instalada até $75 \mathrm{~kW}$ ) e à minigeração distribuída (centrais geradoras com potência acima de $75 \mathrm{~kW}$ até $5 \mathrm{MW}$ ). 
Como única fabricante foi identificada a empresa de pequeno porte Energy Source, localizada no interior do estado de São Paulo, que fabrica baterias com o aproveitamento de baterias antigas por meio de reciclagem. A empresa nos informou que o mercado está aquecido e que vende toda a sua produção, relatando ainda que existe demanda reprimida por conta das dificuldades de importação ocorridas no início da pandemia da Covid-19. Os sistemas off grid respondem por mais de $90 \%$ de suas vendas. Suas baterias recicladas têm menor capacidade e custam um terço da bateria nova.

Segundo nos informou a Energy Source, as baterias de chumbo estão sendo substituídas por baterias de lítio por conta da maior durabilidade e por questóes ambientais, pois as de lítio emitem menos gases poluentes. Por conta do mercado em alta, o fabricante começará a importar células de lítio da China para a fabricação de baterias novas. As células têm posição "ex" na tarifa aduaneira, sem imposto de importação.

Os sistemas on grid atuais raramente adicionam baterias aos equipamentos solares, pois, como foi dito, dispóem da rede para suprir a energia necessária fora do período da incidência solar. No entanto, com a esperada diminuição futura dos atuais subsídios, por meio da cobrança na GD de tarifas que hoje são cobradas na conta de luz dos consumidores sem sistema de energia solar, haverá estímulos para se adicionarem baterias aos sistemas de GD com o objetivo de se armazenar o excedente gerado durante o dia. A adesão à aquisição de baterias dependerá da redução nos preços. Os usuários de sistemas GD que seriam alcançados pela nova legislação poderiam instalar baterias de lítio para armazenar a energia excedente diária, já que, injetando menor quantidade de energia na rede, teriam menos encargos a recolher na energia recebida como crédito da distribuidora de energia.

No mercado internacional, a procura de baterias de lítio para uso em sistemas de geração de eletricidade e em veículos elétricos encontra-se em expansão. Estima-se a queda acentuada nos preços e o aumento da densidade energética das células de lítio em quase 200\%. Esses resultados estão incentivando nos países desenvolvidos, ainda que timidamente, o armazenamento de energia por consumidores residenciais e comerciais ligados a redes de distribuição de energia. Espera-se também a queda acentuada nos preços das baterias de lítio na década que se inicia, havendo estimativa de redução de 8\% ao ano nos preços (BloombergNEF, 2020 apud EPE, 2020). Somente com essa queda esperada nos preços ficaria viável o uso mais comum de baterias nos sistemas on grid.

Não obstante o potencial de expansão dos sistemas solares off grid, e consequentemente da demanda por baterias de lítio, não é possível realizar projeção da capacidade instalada para os próximos anos, como é realizado para a capacidade on grid, pois como a instalação dos sistemas off grid não é alcançada pelo marco legal do sistema de compensação de energia elétrica, isto é, a GD, o Brasil não dispóe de dados estatísticos sobre a capacidade instalada e a evolução recente da energia solar off grid. Consultamos a associação representativa da cadeia produtiva de energia solar, a Associação Brasileira de Energia Solar Fotovoltaica (Absolar), que nos respondeu não dispor de projeçôes de aumento da capacidade instalada de geração de energia solar, on grid e off grid, para os próximos anos.

Para os sistemas de GD on grid, a Empresa de Pesquisa Energética (EPE) realizou projeçóes recentes de expansão da capacidade instalada, como mostra a tabela 1 .

TABELA 1

Evolução da capacidade instalada de geração solar fotovoltaica no Brasil e projeções da EPE para a GD

\begin{tabular}{lrrrr}
\hline \multicolumn{1}{c}{ Solar fotovoltaica } & Dez. 2016 & Dez. 2018 & Out. 2020 & 2025 \\
\hline Geração centralizada (MW) & 24 & 1.798 & 3.114 & - \\
GD (MW) & 57 & 498 & 4.2001 & 10.100 \\
Total solar (MW) & 81 & 2.296 & 7.314 \\
Capacidade total do Brasil - todas as fontes de energia (MW) & 150.410 & 163.441 & 177.671 \\
Energia solar no total do Brasil (\%) & 0,0 & 1,4 & 4,1 \\
\hline
\end{tabular}

Fontes: Brasil (2020) e EPE (2020).

Nota: ${ }^{1}$ Estimativa da EPE. 
A capacidade de geração solar tem crescido de forma exponencial nos últimos anos. A geração centralizada evoluiu $73 \%$ de dezembro de 2018 a outubro de 2020 . Na GD, a taxa de crescimento foi de $740 \%$ de dezembro de 2018 a dezembro de 2020. Em 2019, o acréscimo de potência da GD solar foi maior que a geração eólica (1.400 MW e 900 MW, respectivamente). Para 2025 e 2030, a EPE realizou projeçóes sob duas condiçóes: com a retirada de parte dos subsídios atuais e com a manutenção dos subsídios. As projeçôes variam amplamente de acordo com a manutenção ou não dos subsídios, sendo a projeção da capacidade instalada, em média, 100\% maior se mantidos os subsídios. Para este artigo adotamos as projeçôes menores, sob condição de retirada de parte dos subsídios. Assim, a GD aumenta sua capacidade instalada em 140\% entre 2020 e 2025, e em 300\% entre 2020 e 2030. Essas projeçóes parecem-nos bastante conservadoras diante do crescimento observado nos últimos dois anos $(740 \%)$.

No caso da energia eólica, a Associação Brasileira de Energia Eólica (ABEEólica) projeta que a capacidade instalada dos parques eólicos passará dos atuais 17 mil MW, em 2020, para 27 mil MW, em 2024, ou seja, crescimento de cerca de 60\%. A estimativa foi realizada com os dados dos contratos nos leilóes de energia realizados pela Agência Nacional de Energia Elétrica (Aneel) e do mercado livre, mas, como foi dito, não há uso significativo de baterias nos parques eólicos.

$\mathrm{Na}$ impossibilidade de se realizarem projeçóes sobre a evolução futura da capacidade instalada de sistemas solares off grid, podemos adotar a hipótese de que a procura por essa modalidade de sistema de energia solar apresentará taxas de crescimento em níveis acima das projeçôes realizadas pela EPE para a GD on grid. Essa posiçáo deriva do fato de que, além dos fatores elencados no início deste artigo, que estimulam a demanda por baterias de lítio para sistemas off grid, um fator adicional que poderá ter impacto significativo é a implementação do programa Mais Luz para a Amazônia. Foi estimado recentemente que ainda permanecem sem atendimento de energia elétrica mais de 70 mil famílias na Amazônia Legal, que constituem comunidades isoladas, as quais, pela distância de onde se localizam, não podem ser atendidas pelo sistema convencional das linhas de transmissão das empresas concessionárias. No atendimento àquele número de famílias devem ser adicionadas as atividades econômicas e sociais que com elas coexistem nas pequenas comunidades e que devem ser abastecidas com energia solar, como escolas, igrejas, pequenas manufaturas, resfriamento de alimentos para estocagem, postos de saúde etc.

Em síntese, pode-se adotar como referência mínima para a expansão dos sistemas solares off grid as estimativas realizadas pela EPE para a GD, isto é, $140 \%$ entre 2020 e 2025, e 300\% entre 2020 e 2030, mas com perspectivas de serem maiores, tendo em vista as conservadoras projeçóes da EPE e a implementação do programa Mais Luz para a Amazônia.

\section{REFERÊNCIAS}

BRASIL. Resolução Normativa Aneel no 482, de 17 de abril de 2012. Estabelece as condiçóes gerais para o acesso de microgeração e minigeração distribuída aos sistemas de distribuição de energia elétrica, o sistema de compensação de energia elétrica, e dá outras providências. Diário Oficial, Brasília, v. 149, n. 76, p. 53, 19 abr. 2012. Seção 1.

EPE - EMPRESA DE PESQUISA ENERGÉTICA. Micro e mini geração distribuída \& baterias - estudos do Plano Decenal de Expansão de Energia 2030. Brasília: EPE, set. 2020. Disponível em: <https://bit.ly/32dyl58> Acesso em: dez. 2020.

\section{BIBLIOGRAFIA COMPLEMENTAR}

BRASIL. Resolução Normativa Aneel no 687, de 24 de novembro de 2015. Altera a Resolução Normativa no 482, de 17 de abril de 2012, e os Módulos 1 e 3 dos Procedimentos de Distribuição - Prodist. Diário Oficial, Brasília, 25 nov. 2015.

. Ministério de Minas e Energia. Boletim mensal de monitoramento do Sistema Elétrico Brasileiro - outubro/2020. Brasília: MME, 2020. Disponível em: <https://bit.ly/2PZchc6>. Acesso em: dez. 2020. 


\section{SITES CONSULTADOS}

- ABEEólica. Disponível em: <http://abeeolica.org.br/>. Acesso em: dez. 2020.

- Absolar. Disponível em: <www.absolar.org.br>. Acesso em: dez. 2020.

- Aldo Solar. Disponível em: <https://www.aldo.com.br/>. Acesso em: dez. 2020.

- Energy Source. Disponível em: <https://energysource.com.br/EnergyS/>. Acesso em: dez. 2020.

- EPE. Disponível em: <www.epe.gov.br>. Acesso em: dez. 2020.

- Solius Solar. Disponível em: <https://solius.com.br/>. Acesso em: dez. 2020.

- Unipower. Disponível em: <https://unipower.com.br/>. Acesso em: dez. 2020. 